\title{
THE ASSOCIATIVE STRUCTURE OF THE MENTAL LEXICON: HIERARCHICAL SEMANTIC RELATIONS IN THE MINDS OF BLIND AND SIGHTED LANGUAGE USERS
}

\begin{abstract}
This paper concerns the role of hierarchical semantic relations: class inclusion and partwhole relations as factors organising the mental lexicon, and the dependence of their importance on visual perception and visual memories, as demonstrated by the results of a free association task. 58 blind and 58 sighted language users were instructed to give associations for a list of 75 Polish nouns. Semantic analysis showed that more than $40 \%$ of the whole corpus of answers was related to stimuli through the part-whole or class inclusion relations. The results of the analysis indicated many similarities, concerning both types of relations, in the feedback obtained from the blind and sighted respondents. However, the blind participants showed a significantly stronger tendency to respond with inclusive terms (hyperonyms of the stimuli) than the sighted respondents. The results were interpreted in terms of the specificity of the compensation processes.
\end{abstract}

Key words: mental lexicon, semantic relation, hyponymy, meronymy, visual impairment, blindness, verbal associations

\section{Introduction}

The mental lexicon is conceived as a part of the memory store, which includes a language user's knowledge of words unavoidably used in language comprehension and production. Elements of the lexicon - lexical items - are organised in several ways: among others, on the basis of their semantic aspect. One clear way in which words in our minds can be related in terms of meaning are hierarchi-

Address for correspondence: Nawoja Mikołajczak-Matyja, Institute of Linguistics, Faculty of Modern Languages and Literature, Adam Mickiewicz University, Al. Niepodległości 4, 61-874 Poznań, Poland. E-mail: nawomiko@amu.edu.pl 
cal relations, i.e. class inclusion and part-whole relation. Hierarchies based on these relations reflect the way speakers of a language categorise the world of experience (Cruse, 2000).

However, a problem concerning the universality of such an organisation arises. Does this kind of mental lexicon structure depend, for example, on visual experience? The universality of the organisation within a monolingual lexicon is an issue which can be considered as embedded in the general problem of the language-thought relation.

Among the methods used to reveal the structure of the mental lexicon, one of the oldest and the most popular is the free association test. The history of verbal association tests shows the possibility of interpreting their results both in terms of language processes and behaviour, and in terms of non-language processes which are an area of interest in psychology. The role that experiments using this method play in contemporary research is confirmed by studies carried out over the past dozen years or so. Association experiments and re-developed association norms are used extensively in research into language processing, acquisition of a second language, memory, cognitive development of children, personality, etc. (Houde, 1990; Upmanyu, Bhardwaj, \& Singh, 1996; Moss et al., 1995; Bock, 2002; Forster, 2002; Wolter, 2002; Mikołajczak-Matyja, 2010; and many others).

The subject of this work is the dependence of the mental lexicon structure on visual perception and visual memories. A study concerning this problem is presented, in which the meaning of verbal associations - responses to Polish nouns provided by blind and sighted respondents - was analysed in order to determine the role of class inclusion and part-whole relations as factors organising the mental lexicon.

\section{Review of research}

\section{Class inclusion and part-whole relations as semantic factors determining the mental lexicon structure}

The lexical relation corresponding to class inclusion, for example the class of sparrows included in the class of birds or the class of trees in the class of plants, is often referred to as the "hyponymy relation", where the nouns sparrow and tree are hyponyms of, respectively, the nouns bird and plant (which are hyperonyms of sparrow and tree). Class inclusion or hyponymy is considered by many researchers to be one of the fundamental relations organising the lexical aspect of: natural language, mental lexicon and semantic memory (as a part of long-term memory) (Lyons, 1984; Cruse, 1995, 2000, 2002; Chaffin \& Herrmann, 1984, 1987; Collins \& Quillian, 1972; Murphy, 2003; and many others). Hyponymy organises mainly the parts of lexicon that consist of nouns (and possibly, to a certain degree, also some parts consisting of verbs and adjectives) in hierarchical structures of different levels of specificity, for example oak, tree, plant, organism. The way our 
mind (the mental lexicon or the semantic memory) is organised by hyponymy can be seen as a manifestation of our tendency to classify reality.

"Each entity in our world can be separated into parts: there are parts of objects, parts of events, and parts of abstract things, like ideas, institutions, temporal and space entities" (Pribbenov, 2002, p. 35). Information about the parts of an object and their spatial configuration enables us to infer the form, structure and functionality of the whole object. Therefore, the part-whole connection is considered to be a fundamental ontological relation (Gerstl \& Pribbenov, 1995). The lexical relation corresponding to the part-whole connection is often referred to as the "meronymy (partonymy) relation"; for example, in the relation between branch and tree the noun branch is the meronym of the noun tree (which is the holonym of branch) (Cruse, 1995, 2000). However, there are many differences between parts of material objects and parts of abstract entities, or between parts of objects and parts of events. Thus, meronymy is rather a heterogeneous relation with many subtypes proposed for it, for example: component-object (branch-tree), actor-event (cowboy-rodeo), member-collection (tree-forest), portion-mass (slicepie), stage-process (adolescence-ontogenesis), place-area (oasis-desert), stuff-object (aluminium-bike) (Chaffin \& Herrmann, 1988; Chaffin, 1992).

Hierarchies based on the part-whole relation are considered to have closer links with, i.e. to be "more intimately tied to" (Cruse, 1995, p. 178), concrete physical reality than hierarchies based on the hyponymy relation, because the part-whole relation is more "pragmatic" or based on "more pragmatic associations"; that is, it is more directly based on physical characteristics, spatial and temporal configurations, and functional correlations than hyponymy. On the other hand, hyponymy more directly concerns registering the common features and differences (between class members), i.e. the processes of abstraction and generalisation which organise reality up to the classes denoted by nouns with large extensions such as object, thing, organism, place, material, quality, property, state, or even entity (Chaffin \& Herrmann, 1984, 1987, 1988; Tversky, 1990; Cruse, 1995; Gerstl \& Pribbenov, 1995), while at the top of the part-whole hierarchies are such words as world or universe, which denote "the largest wholes".

The role of both of these hierarchical relations in the mental lexicon structure has been proven by many controlled experiments using, among others, such methods as semantic decision, semantic priming, analogy tests, definitions, the subtest of Similarities from WAIS, as well as different forms of association tests. For example, in English and French association norms (i.e. the dominant or most frequent reactions to stimuli) developed in the middle of the $20^{\text {th }}$ century using the Kent-Rosanoff list of 100 stimuli words there were: 13\% English and $10 \%$ French dominant reactions related to the stimuli by the hyponymy relation, and $8 \%$ of both English and French dominant reactions qualified as holonyms or meronyms of the stimuli (analysis made by the author from the norms reported by Russell \& Meseck, 1959). 


\section{Semantic structure of the mental lexicon in visually impaired people}

Research conducted with sensory disabled people shows the dependence of psychological characteristics and mechanisms on specific kinds of information and data, i.e. auditory, visual, tactual, etc. Comparative experiments conducted with blind and sighted people might uncover a relation between the lack of vision and the way the mental lexicon is arranged. Some features of the linguistic functioning of blind children at the one-word stage regarding, among other things, the level of generality of the word meaning, led to the conclusion that there is a delay not only in creating hypotheses concerning the meaning of particular words, but also in creating general hypotheses concerning words as symbols. The delay is interpreted as a result of an information deficit regarding objects and events of the outside world (Andersen, Dunlea, \& Kekelis, 1984; Dunlea, 1989). According to Tobin (2008), it can be explained in terms of the inadequacy or the inaccessibility of information.

The additional explanation of delays in language development in congenitally blind children can be found in theories considering the development in the light of the ability to recognize the mental states of others and in the light of natural pragmatic factors (Wharton, 2004). For Bloom (2000), children's word learning draws extensively on their understanding of the thoughts of others - in their theory of mind. "Theory of mind underlies how children learn the entities to which words refer, and understand how words can serve as communicative signs" (Bloom, 2000, p. 55). Moreover, for Sperber and Wilson the human cognitive system looks out for "relevant" information: the more cognitive effects gained and the less processing effort expended in gaining those effects, the greater the relevance of the input to the individual who processes it (Sperber \& Wilson, 1996; see also Wharton, 2004). It has been proven that expectations of relevance play a role in lexical acquisition, and that children's hypotheses about word meaning seem to be produced by such a path of least effort (Wharton, 2004, p. 331). Wharton also considers the role of some non-verbal cues in children's word learning: "facial expression, gesture and gaze direction all provide an audience with vital clues as to the mental states of the others" (Wharton, 2004, p. 326). Such cues cannot be perceived nor interpreted by blind children.

However, in later stages - at kindergarten age - most of the differences existing in the language development of blind and sighted people disappear, and results of research on people of school age and adults sometimes even demonstrate the advantage of blind people's linguistic abilities and functioning, e.g. lexical resources, spelling performance or speed of language processing (Sękowska, 1974; Grenier \& Giroux, 1997'; Pérez-Pereira \& Conti-Ramsden, 1999; Lewis, 2003; Röder et al., 2003; Piskorska, 2008).

\footnotetext{
${ }^{1}$ The study of Grenier and Giroux compared the spelling performance of only 7 functionally blind Braillereading students with that of 180 sighted students (using conventional print). Nevertheless, the results indicated a significant difference between the two groups: the functionally blind respondents made less than half the number of mistakes than did their sighted peers (Grenier \& Giroux, 1997).
} 
It is evident that blind children change their conceptual structures and reorganise their lexicon in the process of broadening and enriching their knowledge. However, many linguists and psychologists believe that an evident bilateral relationship exists between representations that underlie linguistic meaning (i.e. semantic representations) and representations that underlie non-linguistic thinking (i.e. conceptual representations) (for discussion cf. Levinson, 1999; also Mikołajczak-Matyja, 2008, 2014; Martínez-Manrique, 2010). On one hand, linguistic behaviour is an important source of information on conceptualisation because it "explicitly encodes and transmits conceptual information" (Pederson $\&$ Nuyts, 1999, p. 4). On the other hand, the lexical (semantic) features of the behaviour are influenced and determined by deeper conceptual systems. According to Aitchison (2003), the concept and the meaning of the lexical unit overlap to a significant extent, but the conceptual knowledge goes beyond the language, that is, there is an inclusion relationship between them: the data on the meaning of the word is contained in the conceptual data. Following this conception, in my recent paper (Mikołajczak-Matyja, 2014) I proposed a solution (connected to the theories suggesting the unstable and complex structure of the concepts) which consists in treating a word meaning as a more stable part of a category representation. The whole mental representation of the category is a potentially variable structure, with its less stable part directly susceptible to changes resulting from new experiences of any kind - verbal and non-verbal, external and internal (inner experience is conceived here as thinking, reasoning, etc. - internal information processing). However, if the contexts of communication situations are forcing the subject to frequent activation of any of the information contained in this part of category representation, it may become a constituent of the more stable part of a category representation - the (subjective) meaning of the word (Mikołajczak-Matyja, 2014). Thus, if such an interdependence between concept and word meaning is, as I believe, the real fact, the functioning of blind language users with no visual experience cannot, at any life stage, be totally identified with the linguistic functioning of sighted persons, because some concepts, and consequently the meaning of some parts of the vocabulary in the lexicon of sighted language users, are determined by visual information. The lack of information could also potentially influence, among other things, the part-whole analysis and the development of the processes of abstraction and generalisation (the basis of the class inclusion arrangement): "Blind children have less access to information necessary for the whole-part analyses. Wholes and parts are often impossible for them to perceive simultaneously, as are multiple properties of single objects or events and shared properties of multiple objects and events" (Mulford, 1988, p. 333).

Many experiments revealing the semantic structure of the mental lexicon, such as semantic differential or enumeration of all the characteristics of denotata of words, show a general similarity between visually impaired and sighted 
language users (for example: DeMott, 1972; Peraita, 1992; see Pérez-Pereira \& Conti-Ramsden, 1999). In verbal analogy tests, tasks with part-whole relations were easier than those concerning opposition and cause-and-effect relations for both blind and sighted respondents aged 9-15 (Pietrulewicz, 1983).

However, some differences, associated to a certain degree with the class inclusion relation, were discovered. In an experiment conducted by Szczechowicz (1976), blind children formed definitions including a hyperonym of the defined word (i.e. classical definitions "per genus et differentiam specificam") at an earlier age than sighted children do.

The pattern of differences and similarities between sighted and blind people across tasks including the hyponymy relation and a verbal process of abstraction and generalisation is rather inconsistent. Many works present experiments in which some level of semantic analysis needs to be performed by respondents before they provide an answer. The most popular test used to estimate abstract verbal reasoning ability is the Similarities test from the Wechsler battery. Subjects are asked to say how two items might be similar (e.g. "in what way are an apple and a pear alike?") and the most correct answers are, in general, simple or compound hyperonyms of the names of compared objects (e.g. fruits). On the one hand, there is evidence that visually impaired children achieve lower scores on the scale compared with sighted children (Tillman \& Osborne, 1969; and Smith \& Mommers, 1976; see Wyver, Markham, \& Hlavacek, 1999). These results were confirmed more recently by a study with an extended list of similarity tasks (Wyver, Markham, \& Hlavacek, 1999) ${ }^{2}$. In a comparable experiment blind children obtained lower results than their sighted peers when instructed to provide common names for different objects (Sękowska, 1974). However, neither Groenveld and Jan (1992) nor Mac Cluskie et al. (1998) found such differences in Similarity testing to the disadvantage of visually impaired people 3 .

It seems interesting to verify the degree of accessibility of the class inclusion relation in blind and sighted people when responses are given somewhat more

\footnotetext{
${ }^{2}$ However, in the study of Wyver, Markham, \& Hlavacek the participants consisted of only 15 children with congenital visual impairments (with only 4 children with severe impairment) and 15 sighted children. Moreover, the authors suggested that the significantly lower scores of participants with severe visual impairments may have been attributable to one participant who scored zero on all items (Wyver, Markham, \& Hlavacek, 1999).

${ }^{3}$ The research of Groenveld and Jan tested the differences in mean scaled scores (including Similarities) on the WPPSI and the WISC-R among three groups: with moderate visual impairment, with severe to profound visual impairment and with near-total and total blindness. The authors did state that "the tendency for totally blind children to have more problems with verbal abstractions (similarities), which was reported by Tillman (1967) and Tillman and Bashaw (1968) did not show up here" (Groenveld \& Jan, 1992, p. 70). The study of Mac Cluskie et al. measured the effects of early-onset vs. late-onset blindness in adults, but it also revealed that in the Similarities test "the raw scores for the late-onset and early-onset groups were similar to the raw score for the sighted, normative population of the WAIS-R" (Mac Cluskie et al., 1998, p. 195).
} 
"automatically", with less analysis. Experiments of this type include, among others, a free association task in which the respondents are asked to provide prompt verbal responses to stimuli-words quickly, without thinking or deliberating over them.

In previous association experiments with blind people the proportions of "visual reactions" (i.e. including information about colour, light, etc.) were often analysed, in comparison with control groups of sighted respondents (as for example in Cutsforth, 1951 and Nolan, 1960; see: Warren, 1994; Szczechowicz, 1976; Wyver, Markham, \& Hlavacek, 2000; Mikołajczak-Matyja, 2004; JaworskaBiskup, 2011). But in some works the relations between associative reactions and stimuli have also been analysed. In Tillman and Williams (1968), Szczechowicz (1976), and Wyver, Markham, \& Hlavacek (2000), proportions of paradigmatic and syntagmatic answers provided by blind and sighted respondents were compared. In an experiment by Szczechowicz, blind respondents gave more syntagmatic reactions than the sighted group, while Tillman and Williams as well as Wyver et al. found no differences between the two groups ${ }^{4}$. In an experiment presented by Elbers and van Loon-Vervoorn (1999), visually impaired and sighted children responded with verbal associations to the same list of nouns four times (a repeated free association task). The coordination relation (as dog-cat) turned out to be more accessible for the blind children than the sighted children, but in general the results indicated a similarity between the associations corpora obtained from the two groups (Elbers \& van Loon-Vervoorn, 1999). The results of the experiment by Mikołajczak-Matyja demonstrated the tendency of Polish language users to give associations that are hyperonyms of stimuli, shown in the most frequent (dominant) responses of both blind and sighted group of respondents. This tendency is only slightly stronger in blind people's answers (Mikołajczak-Matyja, 2004). In the experiment (a free-association oral task) by Jaworska-Biskup only totally blind respondents (and not sighted ones) provided answers categorised as "classification of a concepts to a general category", thus hyperonyms of stimuli (e.g. rainbow - phenomenon) (Jaworska-Biskup, 2011).

The aim of the experiment presented below was to determine whether blind and sighted language users differ in terms of activation of the class inclusion relation and of the part-whole relation during a free association task. Such an experiment makes it possible to determine whether and to what degree the hierarchical semantic structure of the mental lexicon is influenced by visual experience.

\footnotetext{
${ }^{4}$ In the study of Wyver et al. the proportion of paradigmatic associations did not differ between children with visual impairment and sighted participants. However, the authors state that the correlation of age and proportion of paradigmatic responses (the correlation that was significant for the children with visual impairments but not for the sighted children) suggests that differences in the rate of acquisition of reading skills and the contribution of this and other life experiences to the syntagmatic/paradigmatic shift is not the same for the two groups of children (Wyver, Markham, \& Hlavacek, 2000, p. 215-216).
} 


\section{Method}

\section{Participants}

The participants consisted of 116 Polish language users: an experimental group of 58 blind post-elementary schools students and a control group of 58 sighted students. The subjects from the experimental group, aged 13-19, included 31 boys and 27 girls; 23 of them were totally blind, while the remaining 35 had minimal light perception. All of them were congenitally blind or had lost their vision early in life (before the age of 5). They had no other serious handicaps or intellectual impairments. Participants from the control group of sighted people were matched with the blind subjects by age, gender, class and type of school and general achievements as students (as identified by their teachers).

\section{Materials}

The research material consisted of a list of 75 Polish simple nouns, from which the following 25 three-segment semantic fields were distinguished: Trees, Fruit and vegetables, Animals, Parts of the body, People, Groups of people, Body fluids, Food, Appliances, Vehicles, Cosmetics and washing articles, Buildings, Parts of a house, Parts of a room, Trade-service places, Terrain, Landscape parts, Atmospheric phenomena, Materials, Works of art, Time, Sounds, Activities, Emotions, Personality traits. The basis for selecting these semantic fields and the nouns belonging to them was the differentiated (stronger or slimmer) potential possibility of finding hyperonyms, hyponyms, holonyms and meronyms of stimuli words. For instance, it is easier to find a close hyperonym for fox than for hill, a holonym for hand than for joy, a meronym for lorry than for metal, etc. The other criterion of selection was the role of sight in a sighted person's obtaining of knowledge about the noun denotata. Not only such traits of denotata as colour, transparency and polish were taken into consideration, but also other properties, such as size (very large objects, such as a palace, and very small, such as a wasp, can be perceived by blind people only due to specially constructed models, respectively enlarged and diminished), liquid or gas state of matter, and so on. Therefore, the stimuli differed in their degree of "visualness", from "non-visual" names of personality traits (as honesty) or periods of time (as Tuesday), through nouns with some potentially important visual information (as yellow lemon or transparent glass, coloured and liquid beer or green-white and big birch), to totally visual stimuli (as rainbow and lightning).

\section{Procedure}

A free association test was used, in which the participants were asked to write the first word that came to mind when given a stimulus word. This was a written test. The questionnaires for the experimental group of blind people (instructions and lists of stimuli) were printed in Braille, and the respondents also wrote their answers in Braille using Braille machines. 
The experiment was conducted in groups, during school classes or in common rooms of dormitories. All respondents gave their (informed) consent to participate in the research.

\section{Results}

More than 8600 responses were obtained: 4325 from blind and 4290 from sighted respondents. Many reactions provided in response to the given stimulus by different respondents were the same (only completely identical answers or answers that differed only in grammatical number were recognised as the same responses). Therefore, all answers to the given stimuli were arranged according to their frequency, separately for the experimental and for the control group.

A detailed semantic analysis of the whole corpus of answers uncovered part-whole relations and class inclusion relations between stimuli and reactions. In order to make the analysis more objective, some lexicographic explanations of words (from monolingual Polish dictionaries) were used for the purpose of determining semantic relations.

\section{Class inclusion relation}

Table 1 presents the numbers of responses (RN) obtained from blind and sighted participants that could be interpreted as hyperonyms and hyponyms of the stimuli, as well as the results of comparison of their participation rates $(\mathrm{P})$ in total sums of reactions, as measured by the $\chi^{2}$ test of equivalent proportions.

The number of hyponymic/hyperonymic answers obtained from the blind participants is much higher than the number of such responses provided by the control group. The $p$ numbers are very low for both hyperonyms and for hyperonyms + hyponyms, so we may reject the null hypothesis (that there is no

Table 1 . Hyponymy relation

\begin{tabular}{|c|c|c|c|c|c|c|}
\hline \multirow{2}{*}{ Type of reaction } & \multicolumn{2}{|c|}{ Blind } & \multicolumn{2}{|c|}{ Sighted } & \multicolumn{2}{|c|}{ Comparison: $\chi^{2}$ test } \\
\hline & $\mathrm{RN}$ & $\mathrm{P}(\%)$ & $\mathrm{RN}$ & $\mathrm{P}(\%)$ & $\chi^{2}$ score & $p$ level \\
\hline Hyperonyms & 1052 & 24.3 & 750 & 17.5 & 60.94 & 0.000 \\
\hline Hyponyms & 82 & 1.9 & 68 & 1.6 & 1.22 & 0.270 \\
\hline $\begin{array}{l}\text { Hyperonyms } \\
+ \text { hyponyms }\end{array}$ & 1134 & 26.2 & 818 & 19.1 & 62.87 & 0.000 \\
\hline $\begin{array}{l}\text { Total sum of } \\
\text { reactions }\end{array}$ & \multicolumn{2}{|c|}{$4325(100 \%)$} & \multicolumn{2}{|c|}{$4290(100 \%)$} & & \\
\hline
\end{tabular}


difference between the groups) and conclude that the differences between blind and sighted participants are significant.

However, in spite of these differences, relatively high numbers of hyperonyms were obtained from both groups of respondents for similar sets of stimuli, as measured by means of quartile range. Of the stimuli with numbers of hyperonymic answers greater than the upper quartile values, 14 are the same for blind and sighted people (the sets of stimuli with such values contain, respectively, 18 and 17 stimuli for blind and sighted participants). These 14 stimuli are as follows: beech, birch, tomato, carrot, bullfinch, fox, beer, telephone, lorry, tenement house, symphony, novel, Tuesday, scream. Therefore, even if associations related to stimuli by means of hyponymy relations are much more characteristic for blind than for sighted participants, the same nouns typically evoke this kind of associative reaction in both groups of language users.

A hyperonymic answer is often the most frequent reaction (i.e. the dominant association in a group of subjects) to a given stimulus. This is the case with the responses provided by the blind people for 28 stimuli (more than one-third of the list) as well as with the responses provided by the control group for 24 stimuli. The majority of stimuli from these two sets (23) are the same. These are the following stimuli: pine, beech, birch, tomato, carrot, bullfinch, fox, beer, sausage, telephone, lorry, cottage, tenement house, hill, symphony, novel, statue, Tuesday, March, scream, whistle, patter, murder. In the case of 21 stimuli from the set these dominant reactions are shared by the experimental and the control group (for example: bullfinch - bird, murder - crime), and in the case of two stimuli (Tuesday and whistle) the dominant hyperonymic reactions are not the same for the two groups of respondents, but the dominant hyperonymic answer of one group is an association (not dominant) given by the other group.

There is not any evident influence of visualness of stimuli on the analysed differences between blind and sighted language users. For example, on one hand the blind participants provided many more hyperonymic associations than the sighted ones not only to nonvisual stimuli from the Time class, but also to very visual stimuli such as rainbow and lightning. On the other hand, there is no clear difference between the two groups in terms of tendency to provide hyperonymic associations to nonvisual stimuli from the Personality traits class.

In both groups of respondents the tendency to provide responses that could be qualified as hyponyms of stimuli is much weaker than the tendency to give hyperonymic answers. For 12 stimuli at least two blind respondents gave hyponymic reactions, and for 11 nouns at least two sighted respondents responded in this way. Of these two sets, 8 stimuli are the same (hand, poor person, beer, sausage, floor, metal, statue and fear), while for 6 of them at least one hyponymic reaction is shared by the blind and the sighted respondents.

In general, for 62 of the stimuli words a minimum of one hyperonymic or hyponymic answer is shared by the experimental and the control group. 
Table 2. Part-whole relation

\begin{tabular}{lcccccc}
\hline \multirow{2}{*}{ Type of reaction } & \multicolumn{2}{c}{ Blind } & \multicolumn{2}{c}{ Sighted } & \multicolumn{2}{c}{ Comparison: $\chi^{2}$ test } \\
& $\mathrm{RN}$ & $\mathrm{P}(\%)$ & $\mathrm{RN}$ & $\mathrm{P}(\%)$ & $\chi^{2}$ score & $p$ level \\
\hline Holonyms & 425 & 9.8 & 417 & 9.7 & 0.03 & 0.868 \\
$\begin{array}{l}\text { Meronyms } \\
\text { Holonyms } \\
+ \text { meronyms }\end{array}$ & 381 & 8.8 & 358 & 8.3 & 0.59 & 0.442 \\
$\begin{array}{l}\text { Total sum of } \\
\text { reactions }\end{array}$ & 406 & 18.6 & 775 & 18.0 & 0.47 & 0.494 \\
\hline
\end{tabular}

\section{Part-whole relation}

Table 2 presents the numbers of responses $(\mathrm{RN})$ obtained from the blind and the sighted participants that could be interpreted as holonyms and meronyms of stimuli, as well as the results of comparison of their participation rates $(\mathrm{P})$ in total sums of reactions, as measured by the $\chi^{2}$ test. Null hypothesis: there is no difference between groups.

The differences are statistically non-significant. The number of holonymic/ meronymic answers obtained from the blind respondents is slightly higher than the number of such responses provided by the control group, but, with P levels $>0.05$ we cannot reject the null hypothesis. In particular, the number of holonyms are almost equal for both groups of participants (blind: $425=9.8 \%$; sighted: $417=9.7 \%$ ).

Moreover, relatively high numbers of holonyms were obtained from both groups of respondents for similar stimuli sets, as measured by means of quartile ranges: of the stimuli with numbers of holonymic answers higher than upper quartile values, 13 are the same for the blind and for the sighted respondents (the sets of stimuli with such values consist of 18 stimuli for each group). These 13 stimuli are as follows: pine, paw, teacher, brigade, roof, window, wall, ceiling, lightning, metal, glass, concrete, step. The same is true for sets of meronyms: 15 stimuli with numbers of meronymic answers higher than upper quartile values are the same for the blind and for the sighted group (the sets of stimuli with such values consist of 18 stimuli for each group). These 15 stimuli are the following: pine, lemon, wasp, hand, brigade, sausage, cheese, tenement house, roof, window, meadow, river, rainbow, hail, joy. Hence it is the same nouns in both groups of language users that typically evoke associative reactions related to the stimuli by a part-whole relation. 
A holonymic answer is sometimes the most frequent (dominant) association to a given stimulus. This is the case with the responses obtained from the blind group for 10 stimuli, and with the responses provided by the control group for 7 stimuli. Of these two sets, 6 stimuli are the same: paw, brigade, teacher, fight, lightning, glass. Only for the stimulus glass is the dominant holonymic reaction not identical in both groups, but even in this case the dominant holonymic answer of one group is an association (not dominant) given by the other group.

For some nouns, associations classified as meronyms of the stimuli are also the most frequent (dominant) reactions. This applies to the responses obtained from the blind group for 6 stimuli and the responses provided by the control group for 8 stimuli. Out of these two sets, 4 stimuli (meadow, window, rainbow, river) are the same. Only for one of them (meadow) is the dominant meronymic reaction not the same in both groups, but even in this case the dominant meronymic answer of one group is an association (not dominant) given by the other group.

In general, there are 54 stimuli for which at least one answer being in a partwhole relation with the stimulus is shared by the experimental and the control group.

There is no evident influence of the visualness of stimuli on the tendency to provide holonymic or meronymic responses by the blind respondents as compared to the control group. There is no clear difference between the two groups in terms of the tendency to provide associations of this type to visual stimuli. For example, the number of blind participants giving such reactions to the noun rainbow is slightly higher than the number of such reactions given by the sighted group, while in the case of the stimulus lightning the situation is reversed (with the size of the difference being exactly the same).

\section{Discussion}

In general, the experiment confirmed the significant role of hierarchical relations as factors determining the mental lexicon structure: reactions classified as being related to the stimuli by hyponymy and part-whole relations constitute $41 \%$ of the whole corpus of answers obtained from all 116 respondents.

A number of similarities and one clear difference in the performance of the two groups of respondents were found.

Firstly, the results of numerical and content analyses indicate some convergence concerning the part-whole relation. The general tendency to provide responses that can be interpreted as holonyms of the stimuli is similar in both the experimental and the control group. Furthermore, the tendency to answer in this manner is the strongest for rather convergent sets of nouns and these answers are often identical. Associations such as: pine - forest, paw-dog, teacher - school, wall - room, roof - house, glass - pane, etc. are characteristic of the (easily accessible) organisation of lexicons independently of the ability to see. 
The same applies to reactions classified as meronyms of the stimuli: blind and sighted respondents gave similar numbers of such answers, and this tendency is strong for largely convergent sets of stimuli. Many meronyms given by both groups are identical. Answers such as: pine - needle, lemon - acid, bee - sting, roof - tile, meadow - grass, rainbow - colour(s) and many others were obtained from more than one blind and more than one sighted respondent. Thus the inability to see - and the consequent lack of the possibility of perceiving some parts of a whole simultaneously - does not have a very strong impact on connections of this type as factors organising the mental lexicon. Of course, even if it is of great importance, vision is not the only way to grasp the part-whole information concerning material objects.

Secondly, the semantic analysis revealed many similarities between the experimental and the control group concerning the class inclusion relation. The tendency to answer in the free association task with responses that can be interpreted as hyperonyms of the stimuli is the strongest for convergent sets of nouns. Moreover, many reactions of this type obtained from the blind and the sighted respondents for the given stimuli are identical. For almost one-third of the stimuli, identical hyperonymic answers are the dominant associations in the two groups. Thus reactions such as: birch - tree, bullfinch - bird, bee - insect, carrot-vegetable, saliva - secretion, beer-alcohol, sausage - food, bus - vehicle and many others are the most frequent associations for the two groups of respondents. Furthermore, both blind and sighted people demonstrate a rather weak tendency to respond with hyponyms of the stimuli. In fact, it is rather difficult or even impossible to find single-word hyponyms for many of the stimuli words, especially for more abstract ones, e.g. Tuesday. However, responses of this type provided in the free association task can be interpreted as names of prototypic elements of the categories named by stimuli nouns. Thus, some identical hyponyms obtained from both groups, e.g. metal - iron or floor - parquet floor, suggest a similarity of the structure of such categories among the sighted and the blind language users.

However, regardless of all these convergences in the corpora of answers given by the experimental and the control group, the blind participants showed a much stronger tendency to react with hyperonyms than do the sighted respondents. The first reason for this may be the written nature of the experiment. The time taken by a blind respondent to produce an answer is usually longer than that taken by a sighted respondent, due to the specificity not only of the reading process but also of the very technical aspects of writing: necessity of removing hands from the word-stimulus, turning to the Braille machine, etc. This can provide the Braille user with more time to consider his/her reaction. This additional time could result in the more automatic response being replaced by a more formal one, for example a categorising response. However, this explanation seems insufficient. Many researchers believe that no form of association testing, even the oral one, is fully "automatic", i.e. even if the researcher wants to prevent subjects from 
consciously analysing the stimuli, there is always some process of selection of associations during which many "immature" responses (emotional, very personal, evaluating, distant, etc.) are suppressed and replaced with more "mature" or logical ones (Flavell et al., 1958; see also Hunca-Bednarska, 1997). This process can influence reactions in sighted as well as blind participants. Some factors, such as fatigue, tiredness, time-pressure or disease (especially psychosis) can diminish the influence of the selection. But if the additional response time in the blind group is responsible for intensifying the selection significantly, why does it not result in a difference in the number of other types of "more mature" reactions, such as holonyms? One possible answer is the specificity of the list of items used in the experiment. Moreover, as it has been mentioned above (2.2.), in the recent freeassociation oral experiment by Jaworska-Biskup, only the experimental group - blind children (aged 7-9 years) - provided answers qualified as classification of a concepts to a general category (to 5 stimuli) (Jaworska-Biskup, 2011).

Therefore, another (alternative or supplemental) explanation is proposed: all of the results obtained in the study can be interpreted with regard to the specificity of the compensation processes. Direct experience with objects, events and situations, by means of unimpaired organs of sense - primarily the organs of touch and hearing - reduce, to a certain degree, the differences between the information background in the minds of blind and sighted people. The nature of this reduction depends on the possibility or necessity of transforming sensory input into amodal percepts (Heller, 1991; Heller \& Schift, 1991). This transformation can be made by a kind of central processor. However, "only a certain proportion of our conceptual store is formed through direct perception, and even that has to go through central processing, including memory, reasoning etc. The remainder comes from secondary experiences, mainly linguistic" (Werth, 1983, p. 88). Thus, in addition, there is compensation by language. The data obtained in this manner probably have a significant influence on the content and structure of the mental lexicon (as the store of lexical items and the element of language processing), concealing differences in the method of acquiring information and in analysis of objects (for example part-whole analysis). However, information communicated verbally to blind people in order to supplement their knowledge about the world is very often highly organised and structured, sometimes being classified hierarchically, e.g. in the form of category arrangements or definitions with hyperonymic genera. It can be considered as an example of the way some practical strategies shape the cognitive development and, more generally, of the role of social interactions in the development of blind children (for this issue see e.g. Roe \& Webster, 1997).

Of course, not all information available to a blind child is specially structured. Nevertheless, it is possible that the hierarchical arrangements established in this way in blind language users' minds manifest themselves in the partly "automatic" free association task by the activation of hyperonyms to stimuli words. 
In conclusion, the compensatory role of the unimpaired organs of sense and of language results or manifests itself, on one hand, in many similarities in the mental lexicon of blind and sighted language users (the results confirm the assumption about the universality of the structure of the mental lexicon), but also, on the other hand, in the stronger tendency of unsighted respondents to demonstrate a method of systematising reality in their associations. This tendency reflects the importance of world categorisation in (severely) visually impaired people's minds.

\section{References}

Aitchison, J. (2003). Words in the Mind. An Introduction to the Mental Lexicon. Malden, MA: Blackwell.

Andersen, E.S., Dunlea, A., \& Kekelis, L.S. (1984). Blind children's language: Resolving some differences. Fournal of Child Language, 11 (3), 645-664.

Bloom, P. (2000). How Children Learn the Meanings of Words. Cambridge, MA: MIT Press.

Bock, J. K. (2002). Meaning, sound, and syntax. Lexical priming in sentence production. In G.T.M. Altmann (Ed.), Psycholinguistics. Critical Concepts in Psychology. Vol. 5 (pp. 378-404). London, New York: Routledge.

Chaffin, R. (1992). The concept of a semantic relation. In A. Lehrer \& A.F. Kittay (Eds.), Frames, Fields and Contrasts (pp. 253-288). Hillsdale, MI: Lawrence Erlbaum Associates.

Chaffin, R. \& Herrmann, D.J. (1984). The similarity and diversity of semantic relations. Memory and Cognition, 12 (2), 134-141.

Chaffin, R. \& Herrmann, D.J. (1987). Relation element theory: a new account of the representation and processing of semantic relations. In D.S. Gorfein \& R.R. Hoffman (Eds.), Memory and Learning. The Ebbinghaus Centennial Conference (pp. 221-245). Hillsdale, MI: Lawrence Erlbaum Associates.

Chaffin, R. \& Herrmann, D.J. (1988). The nature of semantic relations: A comparison of two approaches. In M.W. Evens (Ed.), Relational Models of the Lexicon. Representing Knowledge in Semantic Networks (pp. 289-334). Cambridge: Cambridge University Press.

Collins, A.M. \& Quillian, M.R. (1972). How to make a language user. In E. Tulving \& W. Donaldson (Eds.), Organization of Memory (pp. 309-351). New York: Academic Press.

Cruse, D.A. (1995). Lexical Semantics. Cambridge: Cambridge University Press.

Cruse, D.A. (2000). Meaning in Language. An Introduction to Semantics and Pragmatics. Oxford: Oxford University Press.

Cruse, D.A. (2002). Hyponymy and its varieties. In R. Green, C.A. Bean, \& S.H. Myaeng (Eds.), The Semantics of Relationships. An Interdisciplinary Perspective (pp. 3-21). Boston, MA: Kluwer Academic Publishers. 
Dunlea, A. (1989). Vision and the Emergence of Meaning. Blind and Sighted Children's Early Language. Cambridge: Cambridge University Press.

Elbers, L. \& van Loon-Vervoorn, A. (1999). Lexical relationships in children who are blind. Fournal of Visual Impairment and Blindness, 93 (7), 419-421.

Flavell, J.H., Draguns, J., Feinberg, L.D., \& Budin, W. (1958). A microgenetic approach to word association. Journal of Abnormal and Social Psychology, $57(1), 1-7$.

Forster, K.I. (2002). Accessing the mental lexicon. In G.T.M. Altmann (Ed.), Psycholinguistics. Critical Concepts in Psychology. Vol. 1 (pp. 270-296). New York: Routledge.

Gerstl, P. \& Pribbenov, S. (1995). Midwinters, end games, and body relations: A classification of part-whole relations. International fournal of HumanComputer Studies, 43 (5-6), 865-889.

Grenier, D. \& Giroux, N. (1997). A comparative study of spelling performance of sighted and blind students in senior high school. Fournal of Visual Impairment and Blindness, 91 (4), 393-400.

Groenveld, M. \& Jan, J.E. (1992). Intelligence profiles of low vision and blind children. Fournal of Visual Impairment and Blindness, 86 (1), 68-71.

Heller, M.A. (1991). Haptic perception in blind people. In M.A. Heller \& W. Schiff (Eds.), The Psychology of Touch (pp. 239-261). Hillsdale, MI: Lawrence Erlbaum Associates.

Heller, M.A. \& Schiff, W. (1991). Conclusions: the future of touch. In M.A. Heller \& W. Schiff (Eds.), The Psychology of Touch (pp. 327-337). Hillsdale, MI: Lawrence Erlbaum Associates.

Houde, O. (1990). Logical categorization: schematic knowledge, categorical knowledge, and image versus linguistic format. A study in six- to eleven-year-olds. Cahiers de Psychologie Cognitive, 10 (4), 343-384.

Hunca-Bednarska, A. (1997). Skojarzenia werbalne w schizofrenii [Verbal Associations in Schizophrenia]. Lublin: Czelej.

Jaworska-Biskup, K. (2011). The world without sight. A comparative study of concept understanding in Polish congenitally totally blind and sighted children. Psychology of Language and Communication, 15 (1), 33-47.

Levinson, S.C. (1999). From outer to inner space: Linguistic categories and nonlinguistic thinking. In J. Nuyts \& E. Pederson (Eds.), Language and Conceptualization (pp. 13-45). Cambridge: Cambridge University Press.

Lewis, V. (2003). Development and Disability. Malden, MA: Blackwell Publishing. Lyons, J. (1984). Semantyka 1 [Semantics 1]. Warszawa: PWN.

Mac Cluskie, K.C., Tunick, R.H., Dial, J.G., \& Paul, D.S. (1998). The role of vision in the development of abstraction ability. Fournal of Visual Impairment and Blindness, 92 (3), 189-199.

Martínez-Manrique, F. (2010). On the distinction between semantic and conceptual representation. Dialectica, 64 (1), 57-78. 
Mikołajczak-Matyja, N. (2004). Skojarzenia słowne niewidomych i widzących użytkowników języka polskiego - studium porównawcze [Verbal associations of blind and sighted users of the Polish language - a comparative study]. Investigationes Linguisticae, 11, 1-17.

Mikołajczak-Matyja, N. (2008). Hierarchiczna struktura leksykonu umysłowego. Relacje semantyczne w leksykonie widzacych i niewidomych użytkowników języka [The Hierarchical Structure of Mental Lexicon. Semantic Relations in the Lexicon of Sighted and Blind Language Users]. Poznań: Wydawnictwo Naukowe UAM. Mikołajczak-Matyja, N. (2010). The superordination relation and the symmetry of verbal associations in selected parts of the mental lexicon. Psychology of Language and Communication, 14 (2), 15-35.

Mikołajczak-Matyja, N. (2014). The distinction between the concept and the meaning of the word in light of theories of concepts structure and of speech processing models. Pensée fournal, 76 (7), 147-164.

Moss, H.E., Ostrin, R.K., Tyler, L.K., \& Marslen-Wilson, W.D. (1995). Accessing different types of lexical semantic information: evidence from priming. Fournal of Experimental Psychology: Learning, Memory, and Cognition, 21 (4), 863-883.

Mulford, R. (1988). First words of the blind child. In M.D. Smith \& J.L. Locke (Eds.), The Emerging Lexicon. The Child's Development of a Linguistic Vocabulary (pp. 293-338). New York: Academic Press.

Murphy, M.L. (2003). Semantic Relations and the Lexicon. Cambridge: Cambridge University Press.

Pederson, E. \& Nuyts, J. (1999). Overview: On the relationship between language and conceptualization. In J. Nuyts \& E. Pederson (Eds.), Language and Conceptualization (pp. 1-12). Cambridge: Cambridge University Press.

Pérez-Pereira, M. \& Conti-Ramsden, G. (1999). Language Development and Social Interaction in Blind Children. Hove: Psychology Press.

Pietrulewicz, B. (1983). Rozwój rozumowania przez analogię u dzieci niewidomych $w$ wieku szkolnym [Development of Reasoning by Analogy in School-Age Blind Children]. Wrocław: Ossolineum.

Piskorska, A. (2008). Concepts reflecting aesthetic judgments in blind children. In E. Mioduszewska \& A. Piskorska (Eds.), Relevance Round Table (pp. 97-108). Warszawa: Wydawnictwa UW.

Pribbenov, S. (2002). Meronymic relationships: From classical mereology to complex part-whole relations. In R. Green, C.A. Bean, \& S.H. Myaeng (Eds.), The Semantics of Relationships. An Interdisciplinary Perspective (pp. 35-50). Boston, MA: Kluwer Academic Publishers.

Röder, B., Demuth, L., Streb J., \& Rösler, F. (2003). Semantic and morpho-syntactic priming in auditory word recognition in congenitally blind adults. Language and Cognitive Processes, 18 (1), 1-20.

Roe, J. \& Webster, A. (1997). Children with Visual Impairments: Social Interaction, Language and Learning. New York: Routledge. 
Russell, W.A. \& Meseck, O.R. (1959). Der Einfluss der Assoziation auf das Erinnern von Worten in der deutschen, französischen und englischen Sprache. Zeitschrift für Experimentale und Angewandete Psychologie, 6, 191-211.

Sękowska, Z. (1974). Kształcenie dzieci niewidomych [Education of Blind Children]. Warszawa: PWN.

Szczechowicz, A. (1976). Swoistość kształtowania się pojęć u dzieci niewidomych [The specificity of concept forming in blind children]. In K. Klimasiński (Ed.), Procesy poznawcze a defekty sensoryczne. Materiaty I Krajowego Sympozjum Psychologii Defektologicznej [Cognitive Processes and Sensory Deficits. Materials of I National Symposium of Defectological Psychology] (pp. 86-99). Warszawa: Polski Związek Głuchych.

Sperber, D. \& Wilson, D. (1996). Relevance: Communication and Cognition. Malden, MA: Blackwell.

Tillman, M.H. \& Williams, C. (1968). Associative characteristics of blind and sighted children to selected form classes. International fournal for the Education of the Blind, 18 (2), 33-40.

Tobin, M. (2008). Information: A new paradigm for research into our understanding of blindness? British Journal of Visual Impairment, 26 (2), 119-127.

Tversky, B. (1990). Where partonomies and taxonomies meet. In S.L. Tsohatzidis (Ed.), Meaning and Prototypes. Studies in Linguistic Categorization (pp. 334344). New York: Routledge.

Upmanyu, V.V., Bhardwaj, S., \& Singh, S. (1996). Word-association emotional indicators: Associations with anxiety, psychoticism, neuroticism, extraversion, and creativity. The fournal of Social Psychology, 136 (4), 521-529.

Warren, D.H. (1994). Blindness and Children. Cambridge: Cambridge University Press.

Werth, P. (1983). Meaning in language acquisition. In A.E. Mills (Ed.), Language Acquisition in the Blind Child. Normal and Deficient (pp. 77-88). London: Croom Helm.

Wharton, T. (2004). Lexical acquisition and pragmatics. UCL Working Papers in Linguistics, 16, 323-341.

Wolter, B. (2002). Assessing proficiency through word associations: Is there still hope? System, 3 (3), 315-329.

Wyver, S.R., Markham, R., \& Hlavacek, S. (1999). Visual items in tests of intelligence for children. Journal of Visual Impairment and Blindness, 93(10), 663-665. Wyver, S.R., Markham, R., \& Hlavacek, S. (2000). Inferences and word associations of children with visual impairments. Journal of Visual Impairment and Blindness, 94 (4), 204-217. 